science $\mathcal{W}$ irect

Consciousness and Cognition 15 (2006) 197-217
Consciousness and Cognition

www.elsevier.com/locate/concog

\title{
Rethinking the ontogeny of mindreading
}

\author{
Maurizio Tirassa*, Francesca Marina Bosco, Livia Colle
}

Università di Torino, Dipartimento di Psicologia e Centro di Scienza Cognitiva, via Po, 14, 10123 Torino, Italy

Received 30 November 2004

Available online 11 August 2005

\begin{abstract}
We propose a mentalistic and nativist view of human early mental and social life and of the ontogeny of mindreading. We define the mental state of sharedness as the primitive, one-sided capability to take one's own mental states as mutually known to an interactant. We argue that this capability is an innate feature of the human mind, which the child uses to make a subjective sense of the world and of her actions. We argue that the child takes all of her mental states as shared with her caregivers. This allows her to interact with her caregivers in a mentalistic way from the very beginning and provides the grounds on which the later maturation of mindreading will build. As the latter process occurs, the child begins to understand the mental world in terms of differences between the mental states of different agents; subjectively, this also corresponds to the birth of privateness.
\end{abstract}

(C) 2005 Elsevier Inc. All rights reserved.

Keywords: Mindreading; Theory of mind; Communication; Consciousness; Subjectivity; Sharedness; Privateness; Social cognition; Nativism

\section{Introduction}

Our ability to represent ourselves and other entities as intelligent agents endowed with beliefs, intentions, emotions, desires, and other mental states has been a major focus of interest for 25

\footnotetext{
* Corresponding author. Fax: +39011815039.

E-mail addresses: tirassa@psych.unito.it (M. Tirassa), bosco@psych.unito.it (F.M. Bosco), colle@psych.unito.it
} (L. Colle). 
years. The function of this ability, which is usually referred to as theory of mind (ToM) or mindreading, is held to be the comprehension, explanation, and prediction of behavior and, in general, the management of our social interactions.

Several recent studies agree on the idea of a two-stage development of this faculty. The first stage is considered to be the early-developing mentalistic reasoning that takes place before or during the second year of life (Baron-Cohen, 1995; Barresi \& Moore, 1996). In particular, some researchers have addressed the infants' ability to interact with others in terms of perception, emotion, and intention, but not in terms of belief (Tomasello, Carpenter, Call, Behne, \& Moll, in press; Tomasello \& Rakoczy, 2003). The second stage of development of the theory of mind occurs when 3- or 4-year-old children become capable of attributing representational epistemic states like belief and knowledge; this capability allows them to pass the classical theory of mind tasks like those based on the False Belief paradigm (Wimmer \& Perner, 1983).

Our theoretical proposal is that mindreading be conceived as an innate faculty whose acquisition begins with the innate ability of sharing mental states with the partners in interaction. This ability is present at birth, or immediately after birth (Bosco \& Tirassa, 1998), and builds on the child's innate recognition of agency. We will give a suitable definition of sharedness as a primitive and innate mental state type: roughly, to be able to entertain the mental state of sharedness ${ }^{1}$ is to be able to consider one's mental states as mutually and overtly known to a partner (see also Airenti, Bara, \& Colombetti, 1993; Colombetti, 1993). The ability to entertain proper theories of the mind, which appears later in infancy, builds on the maturation of the ability to differentiate between those mental states, which are shared and those which are private, as well as on other acquisitions like language and culture.

We take the ontogeny of mindreading to be the maturation of a biological faculty. Our approach is fully compatible with the existing empirical literature, which we, however, integrate in an articulated theoretical interpretation. This interpretation also accounts for early social interactions in a novel way.

\section{Theories of the theory of mind}

Mindreading, or Theory of Mind, is an agent's capability of representing another individual's mental states, so as to be able to understand, predict, and explain his behavior (Premack \& Woodruff, 1978).

This is a crucial pillar of human social life; to be able to understand events in a mind-based framework is a huge evolutionary change, allowing for an array of features and activities that range from mentalistic communication (Grice, 1989) to culture, history, and pedagogy (Premack \& James Premack, 1994).

In this section, we will review the main explanations that have been devised concerning the nature and the ontogeny of mindreading.

\footnotetext{
${ }^{1}$ Different communities give different meanings to the same words. Other researchers would probably refer to this situation as one of common knowledge instead of one of shared belief, and keep the latter term for different usages. We hope that the peculiar definition we will provide of sharedness as a subjective mental state (which is identical neither to the definitions found of common knowledge nor to those found of shared knowledge) will avoid any possible ambiguity.
} 


\subsection{Theories of mindreading}

According to simulation accounts, human beings ground their capacity to mindread in the introspective awareness that they have of their own mental states (Goldman, 1993; Harris, 1991). To understand and predict another individual's actions, we would imagine to be placed in her situation and doing what she is doing. We would then observe what is going on inside ourselves, and attribute to the other agent the mental states that we would have if we were her.

A radical version of this account has been proposed by Gordon (1996). In his view, children would first learn to follow the so-called ascent routines for beliefs and other mental states without possessing the relevant concepts in a full-fledged form. According to the author, it would be from linguistic simulation routines that children would become able to infer the other's mental states.

Simulation accounts have lately gained increasing appeal after the discovery of mirror neurons, which has been interpreted as evidence in their favor (Gallese \& Goldman, 1998; Rizzolatti, Fadiga, Gallese, \& Fogassi, 1996). They remain, however, somewhat obscure concerning the architecture and functioning of the decoupling/simulation processes that they posit, as well as, most importantly for our current purposes, concerning its ontogeny.

According to another body of literature, theory-theory accounts, our knowledge about the mind makes up an everyday framework theory (Carey, 1995; Gopnik, 1993). A mindreader would employ mental states as theoretical constructs in the prediction and the explanation of behavior.

On this view, learning and experience are crucial in the acquisition of mindreading: the child, like a scientist, would conjure up several successive theories of mind, always discarding the current one whenever it is falsified by new data collected. The final result of this process would be the adult's representational theory of mind.

Wellman (1990) has argued that folk psychology indeed holds certain features of scientific theories, like coherence or the presence of a causal explanatory framework. Theory-theory accounts, however, require too much intelligence and cognitive effort on the part of the child; furthermore, they do not explain why all the children would devise the same provisional theories at approximately the same ages. Even more basically, it is not clear why a child would devise the very notion of mental states at all, in the absence of innate features like primitive, irreducible capabilities for introspection and mindreading.

An interesting variation of the theory-theory approach is to construe mindreading as a continuum that goes from the ability to comprehend behavior to the possess of a full-fledged theory of mind. This strategy has been advocated by Whiten (1994) for the comprehension of both the phylogeny of mindreading in primates and of its ontogeny in the human species. As regards the latter, the child would begin as a behaviorist, so to speak, and then grow up to be a cognitivist.

This strategy, however, creates more problems than it solves (Bosco \& Tirassa, 1998). The difference between a behavioral description and a mentalistic one is qualitative, not quantitative; it would therefore be necessary to devise three theories, instead of one: one of the child as a behaviorist, one of the child as a cognitivist, and one of why and how the child would pass from the former position to the latter.

As regards the first of these three theories, being a behaviorist (or an ethologist) is not simpler than being a cognitivist, because it anyway requires to entertain representations; nor is it easier, because the network of facts, events, and relations that it requires to keep in mind becomes exceedingly complex in the absence of mentalistic concepts. 
The second theory, that of the child as a cognitivist, is anyway necessary, the only difference being the age at which it is supposed to be ultimately installed.

Finally, as regards the third theory, that of the transition toward mentalism, to falsify a behaviorist theory would be very difficult for an untrained adult, and exceedingly so for a child. Furthermore, to falsify one behaviorist theory would more probably lead to a more sophisticated behaviorist theory, rather than to a mentalistic one. What the child should reject is not a particular theory cast in behaviorist terms, but the very paradigm of behaviorism; the problem is that such accomplishment would require the child (like the cognitive scientist) to already possess mentalistic concepts, which is precisely what Whiten's proposal is aimed at denying.

Still another group of views, Modularity accounts, maintains that mindreading is not something that a child may learn, but an innate mechanism that undergoes spontaneous development in a favorable environment. The end point of this process would be the child's capability of representing cognitive agents as holding true and false propositions about the world, such as pretending that $\mathrm{p}$, believing that $\mathrm{p}$, desiring that $\mathrm{p}$.

Leslie (1987, 1994a, 1994b) has posited the existence of two processing devices that would allow humans to understand agents' behavior. The Theory of Body Mechanism (ToBy) would appear during early infancy and account for the infant's theory of physical bodies. The Theory of Mind Mechanism (ToMM) would appear at 18-24 months and account for meta-representational abilities; pretend play would be the earliest manifestation of the latter. Baron-Cohen (1995) has claimed that the functioning of ToMM would require the successive activation of a sequence of precursors: an innate intentional detector, followed by an eye direction detector and a shared attention mechanism. ToMM would be safely identifiable at around the age of four, based on the child's ability to understand mental states.

Criticisms may be addressed to modular theories at two different levels. One concerns the very notion of module, and we do not have the space to discuss it at any length here (but see Tirassa, 1999a). The other concerns the ontogeny of social life in the human species, and will be discussed later on.

\subsection{Precursors to mindreading?}

Several of the views we have outlined share at least one assumption, namely that some precursor would pave the way for the appearance of mindreading. Precursors are variously found in gaze monitoring and joint attention (Baron-Cohen, 1995), imitation (Meltzoff \& Gopnik, 1993), the infant's emotional reaction to others (Hobson, 1993), and so on. In this section, we will discuss the nature of these claims and the problems which they give rise to.

Infants, whether or not capable of reading minds, do obviously engage in social and communicative interactions with their caregivers as well as with other adults and children. Among the most striking manifestations of the underlying abilities, at least the recognition of agency, gaze monitoring and joint attention, play, imitation, and social referencing have to be mentioned. Language, once the child has begun to use it, quickly becomes a major means of social communicative exchange.

Several theoretical accounts claim that some or all of these social manifestations have relations with mindreading that are both important and developmental. In other words, these abilities are often viewed as precursors of later mindreading abilities, rather than as manifestations of true mindreading or as just unrelated to mindreading. 
Baron-Cohen (1993, 1994), for example, has argued that understanding the mental state of attending-to is a crucial precursor to a more general understanding of mental states. Other researchers have suggested that imitation, emotion sharing, and mindreading proper are increasingly richer manifestations of the ability to form and co-ordinate representations of oneself and of the others (Meltzoff \& Gopnik, 1993). Hobson (1993) has argued that the main precursor of mindreading is the infant's emotional reaction to others. Garfield, Peterson, and Perry (2001) have proposed a Shared Attention Mechanism as the innate precursor of mindreading, along with the capability of discriminating the mother's voice and the disposition to preferentially look at human faces (they have argued, however, in favor of a conception of mindreading as expertise, rather than as an innate faculty).

Whatever their further differences and respective merits, there are some problems with these approaches that we would like to discuss. The general issue is that the very concept of precursor is ill-defined, which generates in turn at least three more specific problems.

The first problem is that the notion of precursor clearly points to some logical and chronological, as opposed to just chronological, sequence. Thus, for example, one might want to claim that an early cognitive function causes or guides, or contributes in causing or guiding, the later appearance of another; or that the latter is a more developed version of the former and therefore somehow subsumes it; and so on. However, precisely what type of logical sequence is hypothesized in the development of mindreading, and why, is often unclear, with the consequence that most of these accounts are mere chronological sequences; yet, just because one cognitive function appears at an earlier age than another does not mean that the former is a precursor of the latter.

The ontogeny of an organ or function (whether mental or otherwise) should instead be understood and described in terms of an initial state, a developmental dynamics, and possibly a final (mature) state. Most of the theories we have mentioned do not discuss the issue of the initial state, thus leaving space to the assumption that such state is blank. This is impossible, both for general reasons (because nothing will develop from blank) and for reasons specifically concerning mindreading (because, as we will argue in a later section, infants cannot be assumed to have no social life, or a social life that be grounded in a non-mentalistic perspective).

The alleged precursors of mindreading can serve neither as its initial state nor as steps in its developmental dynamics, because of the second problem that we see with the notion of precursor. Theories cast in these terms apparently conceive of performance (that is, a type of behavior) as the precursor of a competence (that is, a cognitive function, like mindreading). Joint attention, to name one, is something that a child does; to explain it by appealing to a "specialized inner device whose functioning enables the child to act out joint attention" is unlikely to shed any light on the child's mind. In general, to just posit a suitable piece of internal machinery for each type of behavior observed (that is, to posit that an infant is capable of imitating because she is endowed with an imitation device or module, and so on) offers no explanation. Just because such line of reasoning is so widely diffused in contemporary psychology does not make it more informative.

We are not asserting that theories of the ontogeny of mindreading cast in terms of precursors claim that social behaviors are internalized and become cognitive functions; as far as we understand, few would intentionally do such a move. Nonetheless, because they do not make clear what else is supposed to happen, they do expose themselves to this sort of criticism.

The third problem with the notion of precursor is that imitation, joint attention, and so on, are something that a child will only do every now and then. One might then wonder what a child's 
social life will be the rest of her time. The notion of precursors does not shed any light on this question either. Furthermore, any behavior is reasonably performed only against the background of a certain worldview on the part of the behaving agent (Carassa, Morganti, \& Tirassa, 2004, 2005; Tirassa, in press). For example, to try and share attention with a certain entity of the world, an agent would first have to represent that entity as (among the rest) apt to share attention with. You just do not share your attention with an entity which you do not think can share attention with you. This points to the need of a suitable subjective ontology in charge of providing such background for, and therefore to make sense of, an agent's representation, action, and reasoning.

\section{Theories of the early acquisition of mindreading}

It was held for a long time (Freud, 1911; Piaget, 1936) that the newborn baby's world is solipsistic and that human beings are born unable to differentiate between the stimuli that belong to the self and those that belong to the environment.

An impressive amount of contemporary research has challenged the traditional belief in an initially undifferentiated state. It has been shown, for example, that young infants are highly sensitive to the contingent relations between their physical responses and consequent stimulus events (Papousek \& Papousek, 1974; Rochat \& Morgan, 1995). Habituation studies have suggested that 5- to 6-month-old infants discriminate grasping hands from other, inanimate, physical objects (Woodward, 1998). Most researchers interpret these findings as proof that children in the first 6 months of life are capable of differentiating their own body from other bodies and objects.

On the basis of these initial skills, some authors (Gergely \& Watson, 1996; Thompson, 1998) have argued in favor of a developmental progress from non-mentalistic to mentalistic interactions. Children would begin treating others as entities with whom to share actions, and grow up to treat them as persons with whom to share goals and intentions. These researchers have argued that early affective and social interactions can be explained without assuming a mentalistic worldview on the part of the young infant. In this perspective, the infant's social life consists of interactive behavioral exchanges whose contingency structure suffices for an explanation of the infant's behavior, with no need for mentalistic factors to be introduced. Gergely and Watson $(1996,1999)$ have thus assumed that infants initially are incapable of viewing others as intentional agents or of reading their minds, and that they simply deploy a contingency-detection mechanism, which is part of their perceptual system. These authors have suggested that the infants' innate social reactivity, as it surfaces for example in their early contingent affect-regulative interactions, serves to establish a precondition for intersubjectivity, and that the latter will only appear during later development.

It is a major feature of this position that infants would pass the first part of their life without reading minds. This situation has been commonly associated with autism, a syndrome that has been thought to consist in (or at least to include) a severe impairment of mindreading abilities, which would result, among the rest, in severe social impairment. The picture would thus be that of all infants as pseudo-autistic beings; the majority of them would grow up to a normal life, while an unlucky minority would forever remain there, ending up in full-fledged, clinically manifest autism. This picture does not seem to us to provide a viable strategy for understanding early infancy. We shall instead argue that mindreading is an innate capacity, present in human beings from the 
beginning of their life; we shall also argue, however, that this does not mean that such ability remains unchanged from infancy to adulthood.

The first part of this claim is supported by empirical evidence that very young infants do discriminate and actively orient toward other human beings (Stern, 1985). Indeed, current biosocial views of emotional development hold that mother and infant form an affective communication system since the very beginning (Bowlby, 1969; Stern, 1985; Trevarthen, 1979); the mother's role in such system is to modulate the infant's affective states. The caregivers often engage in facial and vocal mirroring of their baby's displays of emotion, to regulate her affects (Gergely \& Watson, 1999).

On the basis of these findings, it is possible to claim that mindreading appears, in one form or another, at birth; this claim, however, lends itself to different theoretical interpretations.

Fodor (1992), for example, has viewed ToM as an innate faculty, which is already present at birth in its adult form. The changes in the child's performance over the first years of life would not depend on a modification in the innate database that concerns folk psychology, but on the maturation of the child's working memory and reasoning capabilities, which would allow her to operate upon that database with increasingly more sophisticated heuristics than those she could deploy at an earlier age.

We are sympathetic with Fodor's claims that mindreading is innate and that its acquisition does not involve developmental discontinuities or gaps. However, to conceive of the child's mind as straightforwardly identical to that of the adult's (minus memory span) is an ad hoc strategy, only necessary if mindreading (and, in general, cognition) is conceived of as literally being a deductive system operating over a knowledge base. In other words, Fodor's account depends on the previous acceptance of the computational postulate on the nature of the mind (Fodor, 1975, 1987), a position which we do not subscribe to.

If cognition is instead conceived of as a biological phenomenon (Edelman, 1992; Searle, 1992; Tirassa, 1999a, 1999b; Tirassa, in press; Tirassa, Carassa, \& Geminiani, 2000; Varela, Thompson, \& Rosch, 1991), then ontogeny-a notion that is more akin to maturation as it is conceived of, for example, in embryology, rather than to learning or development as they are usually conceived of in psychology_-becomes a more natural explanatory strategy.

A whole body of literature ascribes some capabilities of mindreading to the infant. Infants have a species-specific sensitivity to human facial, vocal, and behavioral displays that modifies based on experience during later development (Meltzoff \& Moore, 1989; Morton \& Johnson, 1991). And, not only are infants capable of recognizing other human beings as similar to themselves, but they also do show an early ability to interact with them. A 42-min-old neonate will turn his head or protrude his tongue as an imitation of a model (Meltzoff \& Moore, 1983). Meltzoff and Gopnik (1993) have argued that imitation and mindreading itself are increasingly complex manifestations of the ability to form and co-ordinate representations of oneself and of the others. In particular, Meltzoff and Moore $(1983,1997)$ have suggested that infants understand that other persons are autonomous agents because they recognize them as "like me" ever since birth.

However, Tomasello (1999), while acknowledging the infant's precocious abilities, has remarked that this "like me" stance plays no actual role in Meltzoff and Moore's account of the subsequent development of mindreading, which is instead cast in a "theory-theory" framework (see Section 2.1).

It may be added that for the infant to conceive the other as "like me" would imply to believe that, since she herself is hungry sometime, her caregiver also is hungry sometimes, or that, since 
she herself suffers sometime, her mother also suffers sometimes, and so on. There is, however, no reason to think that the infant has the capability and the interest to deal with the mental states of her caregivers'.

Furthermore, since the infant cannot be supposed to entertain explicit autobiographical memories or prospects and to reason on non-current situations and thoughts, a "like me" perspective would imply that, at each instant in time, the thoughts and feelings that she would ascribe to the caregiver would be the same that she herself entertains in that very instant: thus, when she is hungry she would think that her caregiver is hungry, when she suffers she would think that her caregiver suffers, and so on. This would neither help the infant to make sense of the caregivers' actions, nor provide a basis on which she could ground sensible social interactions with them.

Our claim will instead be that the infant has no representation of what her caregivers think when they are by themselves, but that she shares her own mental states with the caregivers, with no specific interest about their private mental states.

Finally, to conceive of the others as "like me" would tell the child nothing about what they know about her, what they feel toward her, and what they share with her. If there were no sharing of her mental states, the infant would find herself in a universe in which she would recognize the existence of other agents similar to her, but could have no contact with them.

A third body of literature has taken an intersubjectivist position, according to which infants are born with an innate capability of identifying and ascribing mental states like intentions and feelings, which they would be introspectively aware of (Braten, 1992; Stern, 1995; Trevarthen, 1993). Infants would recognize their own mental states as similar to the corresponding ones of the other humans and would experience such states as "being shared" with them. Stern (1995, p. 420), for example, has suggested that "from a very early age, the infant perceives intentions in the self and the other" and that he "sees past" overt behaviors to read in them the intentions that organize them.

Trevarthen (1993) has suggested that infants are born with a dialogic mind and with an innate sense of a "virtual other". He has claimed that the richly affective interactive exchanges that can be observed between mothers and infants imply what he has called "primary intersubjectivity," primary intersubjectivity would be measurable as the level of contingency between the behavior of the mother and that of the infant. Trevarthen $(1998,2001)$ has further developed his theory of intersubjectivity, arguing that human beings are equipped at birth with capabilities for sympathetic and co-operative mental life; according to him, infants are born with motives that bring them to use communication with trusted companions to learn about intentions, interests, and feelings, and to give joint interpretations of a common reality. But there is even more than that. According to Trevarthen and Aitken (2001), the infant is conscious, since birth, of the others' subjectivity; that is, she would be conscious of another person's mental states and react in communicative, emotional ways so to link each other's subjectivity.

Our theoretical position crucially differs from Trevarthen's concerning the latter point. We argue that infants are indeed aware of another person's mental states, but in a particular form that we call sharedness. As we shall argue, sharedness is the infant's capability to take it for granted that the caregiver is aware of her mental states and will act accordingly. This means that the infant is aware of the others' subjectivity only as far as their interaction is concerned, and that she has no perception of or interest for the others' mental states per se. 
On the basis of studies of primary intersubjectivity, Tomasello et al. (in press) have also argued that human infants share their behavior and emotions with their caregivers and that they are able to engage in a dyadic interaction. Tomasello and Rakoczy (2003) have suggested that the next step in the child's ability to mindread takes place at around 9 months of age, when she commences to understand intention and attention.

An amount of empirical evidence points at this age as the moment when a qualitatively new level of understanding of goal-directed action is acquired. This seems to involve the ability to differentiate goals from the means that can bring them about, to modify an action so as to make it fit for a new situation, and to choose the means that will most efficiently bring about the desired goal.

At around 9-12 months of age infants also become capable of triadic engagement, that is, of interacting with a partner with the aim of bringing about a shared goal (Tomasello et al., in press). Tomasello (1995) has suggested that the appearance of joint attention in the second year of life is evidence of the infant's emerging understanding of others as intentional agents and that mindreading will later build on this early social ability. According to Tomasello and Rakoczy (2003), while the understanding and sharing of intentions emerges at around 1 year of age, the understanding of beliefs emerges years later. More recently, Tomasello et al. (in press) have claimed that the understanding of beliefs and desires is not basic in human cognition, but that it is instead derived from the understanding and sharing of intentions.

Intentionality and sharedness play a crucial role also in the work of Barresi and Moore (1996). Their model of social understanding describes how, in a developmental perspective, social organisms represent the intentional relations of their own and of other agents'. Barresi and Moore have argued that the information available to an organism about its own intentional relations (first-person information) is qualitatively different from the information that the same organism has about other agents' intentional relations (third-person information). In their model, an agent's capability of handling and integrating these different types of information can go through several levels of increasing complexity. In particular, at around the first birthday infants are capable of representing intentional relations that are shared with other individuals; at 18 month of age they develop the notion of intentional agent - that is, they become capable of separately representing themselves and others - and finally, at around 4 years of age, they acquire the capability of imagining themselves or others in situations that are clearly distinct from the real one.

The main difference between our proposal and those that we have just described of Tomasello and colleagues and of Barresi and Moore resides in the notion of sharedness that each adopts. While these other researchers tend to use the term to refer to activities carried about together, like joint attention or the unfolding of a joint action plan mutually known to the interactants (like a social game), we use it in a more mentalistic sense.

Our notion of sharedness - which we hope will become clearer in the next section-refers to a peculiar mental state type: roughly, the one that characterizes a situation in which an agent believes that another agent mutually knows her thoughts and feelings. Our definition of sharedness resembles that which is usually given of common knowledge, except that (a) we take sharedness to be subjective: it is, to repeat, a mental state type (that is, a type of representation) and not an objective state of the world; and that (b) the circularity that it involves is primitive instead than derived.

Sharedness is, in our view, the foundation on which joint activities may also be carried about: it thus can provide at least part of the foundations on which the notion of sharedness used by Tomasello and colleagues and by Barresi and Moore can lie. 


\section{The ontogeny of mindreading}

We take the ontogeny of mindreading to be the maturation of a biological faculty. That we describe it as a sequence of steps does not mean that we posit developmental or qualitative gaps or discontinuities in it, or that we conceive of it in terms of a sequence of Piagetian stages of development. There can obviously be no gaps or discontinuities in the ontogeny of an organ or faculty, and every event that takes place during such a process is rooted in the biology of the species to which the organism belongs. The "steps" that we will describe should rather be viewed as just snapshots of a continuing process, taken at intervals of time.

It is another assumption of ours that children do have a representational mind from the beginning. However, we do not take representations (whether in the child or the adult) to consist in propositions in a database that literally encode the individual's knowledge of the world, the inferences that he or she can legitimately draw from such knowledge, or the behavioral rules that he or she has to follow. Instead, mental representations are conscious and intentional, that is, they consist in different types of semantic relations between the mind and the world (Searle, 1983, 1992; Tirassa, in press).

Mental representations may be described as mental states like beliefs, shared beliefs, sharedness, expectancies, desires, intentions, communicative intentions, hopes, fears and so on. The architecture of cognition may therefore be described in terms of what types of mental states and/or what types of contents characterize the mind (Tirassa, 1999a), and the ontogeny of cognition may be described in terms of what mental states and/or what contents characterize the mind at different ages. Let us repeat that this is not to say that there are literally mental states with propositional attitudes and contents "inside" the mind: while the use of such jargon may help in the development of suitable theories of cognition, mental representations are mental representations, not static predications about the world.

Taken together, these assumptions imply that, although the kinds of interactions that an infant carries out with her partners may differ, under certain respects, from those of an elder child or an adult, they are, nonetheless, those that are typical of an agent endowed with epistemic, emotional, and volitional states-more precisely, those that are typical of the human species.

\subsection{Step $I$}

Human beings have mental states like perceptions, beliefs, intentions and emotions ever since the beginning of their life. As we have discussed above, this does not necessarily mean that infants have "metarapresentational" concepts of these states, that is, representations about representations, let alone representations about another person's representations, as would be needed, for example, to solve the false belief task. Rather, what they have is epistemic, emotional, and volitional states about relevant properties of the surrounding environment, including expectations about what will happen in the situation in which they find themselves.

For example, there is evidence that very young infants are capable of making inferences about the motion of objects that are temporarily out of sight, in accordance with the principle that there is no action at a distance. Three-month-old babies look at an unexpected physical sequence (like one depicting an object that causes another to move without touching it) for longer than at the corresponding "natural" one (that is, an object causing another to move by touching it) (Baillargeon, 1995; Spelke \& Van de Walle, 1993). 
Spelke (1994) has argued that this kind of experimental evidence shows that infants have initial knowledge of the world that is innate and domain-specific. We add that such evidence also suggests that the baby's knowledge manifests itself, among the rest, as expectations - that is, a form of belief - concerning the dynamic evolution of a certain situation.

The infant's knowledge is in no way limited to the physical world. Woodward (1998), for example, has pointed out that by 6 months of age infants have expectation about human animate actions and thus are able to predict what the other persons will do in familiar contexts. Woodward's finding was that infants of that age expect a person's hands to do the same action, like reaching for a certain object, as they have done before. Again, we interpret these findings as evidence that young infants have beliefs that drive their expectations and their reactions to other persons' behavior.

The crucial suggestion that we want to make here concerning the social life of young infants' is that they also have a peculiar form of belief, which we call sharedness. We argue that the recognition of (at least certain) other individuals as agents is innate in humans, and that this allows infants to share all of their mental states with the caregivers (Bosco \& Tirassa, 1998).

We define sharedness as a primitive and innate mental state type which can be characterized in the following terms: to be able to share is to be able to consider one's own mental states as mutually and overtly known to a partner.

Our notion of sharedness resembles in part that of shared belief as defined by Airenti et al. (1993) and Colombetti (1993). In particular, what we borrow from them is the property of circularity that, like them, we attribute to sharedness. Circularity here means that what an agent takes as shared with another has, in her subjective perspective, two features: (a) it is known to this other agent; (b) that the first agent takes it as shared with the other is also known to this other agent.

However, differently from these authors, we take sharedness to be an innate mental state which is present at birth, or immediately after birth, and we focus our theoretical argumentation on this early step of the infant's mental development. This has consequences on the inferential properties of sharedness, that are outlined below.

A further difference in our approach, with respect to Airenti, Bara, and Colombetti's, is that we inscribe our notion of sharedness in a biological, instead than computational, view of cognition.

Ontologically, sharedness is similar to the other epistemic mental states: that is, it is unilateral (being a mental state, it is located, so to speak, inside an individual agent's mind/brain), and therefore entertains with "objective" truth the very same relation that standard beliefs do. Thus, I can share the belief that it is raining with you even if you do not actually share the belief that it is raining with me, in very much the same way that I can believe that it is raining while you believe that it is not.

Also, sharedness is primitive, that is, irreducible. This means that it neither requires, nor is based on or inferred from, any sequence of "nested" beliefs of the "I believe that you believe that I believe..." kind; such nested beliefs may instead be legitimately derived from what is shared (see the discussion in Tirassa, 1999a). In other words, the legitimate logical inferences that I can draw from my sharing that $p$ with you are that I believe that you believe that $p$, that I believe that you believe that I believe that $p$, and so on (but not, of course, that you do indeed believe that $p$ - that concerns your mind, to which I have no direct access).

To say that these are the legitimate implications of my sharedness does not mean that I will have to infer them each time I entertain a shared mental state with you. Indeed, what we claim 
is precisely (a) that the infant is capable of entertaining shared mental states, but not of drawing the inferences that would logically follow, and (b) that she experiences all of her mental states as shared with her partners in interaction, that is, she is unable to experience her mental states as solely of her own.

This means that all of an infant's mental states would, in her perspective, be placed in the cognitive space that she shares with the individuals that surround her, and that all of her actions would take place in the very same space. As sharedness is the grounds on which human communication builds (Airenti et al., 1993; Tirassa, 1997, 1999a), this further implies that, in the infant's subjective world, all of her actions would have a communicative meaning directed at the caregivers (beside, of course, whatever other meanings they may have to her).

Thus, for example, when an infant is hungry, or wants to engage in a social game, she would not need to plan a specific communicative act to the effect that the caregiver comes to recognize such desire and to satisfy it, like an adult would. Instead, she would simply take it for granted that the caregiver is aware of her desire and will act accordingly. Her cry if the adult does not do so can then be interpreted as a reaction to the violation of an expectation about what "naturally" ought to happen in the world. Subjectively, this expectation would only be legitimate if the infant's mental states were public - else, to cry would just make no sense. (An alternative explanation of cry in terms of "reflexes", even provided it could arrange for the case of hunger, could never explain why the child should cry when the caregiver does not engage in the social interaction which she is proposing, or retreats from an interaction in course.)

In this perspective, egocentrism in early childhood would not depend on the infant's inability to view her conspecifics as endowed with mental states, but on her inability to understand that they do not necessarily share her own ones.

This theory does not contradict the empirical evidence that the infant does not understand that other individuals have mental states of their own, qualitatively similar, but not necessarily identical, to those that she entertains. Our point is that there are two interpretations of this evidence, not one. While the standard interpretation is that infants are born subjectively alone and have to become social - at least in terms of what human social life is - during development (see Section 3), the interpretation that we propose is instead that they live in a subjectively ever-social world where everybody (or, at least, their caregivers, which amounts approximately to everybody, in a very young child's perspective) is naturally and spontaneously aware of their feelings, thoughts, experiences, etc.

Sharing mental states, in infancy as well as at any other age, is made possible by the basic identity of the cognitive architectures of all human beings, which allows each of us to recognize the others as similar to ourselves, and therefore to view them as plausible partners for mentalistic interaction (Tirassa, 1997). This capability has to be innate, if only because it would be impossible to learn, and even to conjure up, that other beings with mental states similar to ours exist (see also the discussion in Section 2.1).

If we are right, however, there is a difference in the scope and role of sharedness at different ages. Sharedness in the adult is a matter of ascription: we take as shared with a partner only those mental states for which we have actual reasons to do so, based for example on physical or cultural co-presence (Clark \& Marshall, 1981; Colombetti, 1993). We know, however, that most of our inner states are private of our own and may become shared with a partner only if we decide, and successfully manage, to act so that they do. That is, sharedness in the adult is 
the counterpart of privateness. In our view, sharedness in the infant is instead a plain state of the world: subjectively, the infant would neither have a privateness of her own nor understand that adults do.

Thus, all that is needed for sharedness in the infancy is a primitive, innate recognition of agency, that is, of the entities with which mental states are shared. This is precisely the agent-based subjective ontology that we have mentioned above.

This capability can safely be ascribed to very young children (Leslie, 1994a; Premack, 1990). Infants of 6-12 weeks of age are capable of discriminating human beings from other entities (Brazetlon, Koslowsky, \& Main, 1974; Murray \& Trevarthen, 1985). This implies that they can recognize whether a certain object is an apt candidate for communicative interactions (Hains \& Muir, 1996).

Actually, not only are infants capable of recognizing other human beings as similar to themselves, but they do also show an early ability to interact with them. Starting from the second month of life, infants react differently to a person who is speaking to them than to one who is speaking to someone else (Trevarthen, 1977). Starting from 2 months and a half, they will react differently and appropriately to different emotions displayed by their mother (Haviland \& Lelwica, 1987). Around the third or fourth month, they are willing to engage in turn-taking interactions with their caregivers (Stern, Jaffe, Beebe, \& Bennett, 1975), and will respond with gaze aversion and facial signs of disappointment when their partner suddenly ceases to interact (Tronick, Als, \& Adamson, 1979). Six-month-old babies prefer to look at an adult's face when it is looking at them than when it is looking away (Papousek \& Papousek, 1979), and will respond to an adult's negative expressions with a negative expression of their own (Charlesworth \& Kreutzer, 1973).

These interactions are asymmetric: while the adult is perfectly capable - minus errors, of course - of discriminating between those mental states that are private and those that are shared, the infant takes all of her states as public. This asymmetry is adaptive, because infants are materially and emotionally dependent on adults and because it is required to guide their further achievements.

The infant's capability of sharing mental states with the caregivers allows her to generate expectations about the latter's behavior and therefore, via the protointeractions and the expectancy violation cycle we have described above, to guide it. At the same time, she will focus her attention on the well-defined entities with which she shares her mental states - those entities that are "good to interact with". This helps the caregiver to communicate with the infant and thus to begin the implicit and explicit pedagogy which is crucial for the acquisition of language, culture, and the other products of humans' highly peculiar biology. ${ }^{2}$

Thus, the asymmetry of adult-infant interactions does not contradict the basic identity of all human beings' cognitive architecture. Such identity means that human cognition rests on the same subjective ontology from the beginning, not that the infant is an adult with a smaller body and a deficient working memory. This asymmetry, in this sense, is just a detail: what really matters is

\footnotetext{
${ }^{2}$ It may be interesting to remark that most features of human social life rest on our capability of sharing mental states with one another (see for example Premack \& James Premack, 1994; Searle, 1995). If children had no such capability, albeit in an early form, they would find themselves thrown out of the social life of their species.
} 
that human cognition is the same from the beginning, which allows for properly human-like interactions at any age.

\subsection{Step II}

Toward the end of her first year of life, the infant has achieved a degree of freedom and autonomy that, while still remarkably limited when compared to an elder child or an adult, is nonetheless immensely superior to that she used to have in the previous months. This progress finds a necessary counterpart in the beginning of her ability to discriminate between the mental states entertained by different agents: it would be no more adaptive to take all of her mental states for shared with the caregivers.

True mindreading thus commences as the child ceases to share all of her mental states with the caregivers, that is, when she stops taking it for granted that they are aware of her mental states and begins to wonder what then they will think and how to have them think what she wants them to (and much later, of course, how to have them not think what she does not want them to). In our view, therefore, the appearance of true mindreading does not coincide with the beginning of sociality, but with what is, in a sense, a restriction of it, namely, with the beginning of privateness.

More precisely, the second step in the ontogeny of mindreading takes place when the child begins to understand that each individual has mental states which are private of his or her own; that these states, while qualitatively similar to those of the others, are nonetheless not necessarily identical to them; and that only some of an individual's mental states are actually shared with others. This means that she also begins to understand that something has to be done when one wants to make a state of her own shared with a partner. This is only possible when she begins to understand that she has such private states in the first place, that is, when she begins to understand that sharedness is not a plain matter of fact but something that sometimes occurs and sometimes does not.

This is also the beginning of the subjective difference between private actions and communicative actions. If sharedness can no longer be taken for granted, something has to be done to make a mental state of one's own actually shared with a partner; conversely, certain thoughts and certain actions may take place on a purely private basis, with no need to share them with anybody and everybody. Publicity and privateness thus become, at least in part, a matter of choice.

In the very same way, it begins to become understood that something needs be done when a breakdown occurs in interaction: to just start crying is no solution any longer - at least, not always. Crying may thus become a means of communication among the others; a rhetorical means, so to speak. The beginning of language use also plays a crucial role in this new conception of action and social action.

From the empirical viewpoint, a remarkable body of evidence points to the second half of the first year as a crucial passage toward the comprehension of interindividual differences.

Children of this age begin to understand that other people may not see what they themselves see, and thus become capable of distinguishing their own visual perspective from that of others (Flavell, Everett, Croft, \& Flavell, 1981; Lempers, Flavell, \& Flavell, 1977).

At around the same age, the toddler begins to turn her eyes toward where another person is watching, that is, she becomes capable of following the partner's gaze and of establishing and monitoring joint visual attention on a third-party object (Butterworth, 1991; Scaife \& Bruner, 
1975). This can be interpreted as proof that she recognizes the partner as an agent endowed with his own private mental states. If the child looks in the same direction as the partner does, that means (a) that she recognizes the partner as a being similar to herself, that is, as an agent capable of perceiving and representing the environment in a way similar to herself; but also (b) that she recognizes that the partner has a different visual perspective from that which she herself has, that is, not everything is shared. While (a), as we saw, is necessary for human social interactions at any age, (b) is a new acquisition; if (b) were not true, then there would simply be no point in turning one's own gaze or in monitoring the partner's gaze. Indeed, that is something that younger children do not do.

Very much the same holds for other features of social interactions. Protodeclaratives and protoimperatives appear around the end of the first year of life (Bates, Benigni, Bretherton, Camaioni, \& Volterra, 1979); they are mostly acted out by means of gestures like pointing, but also by means of the first words uttered. At the same age, the child also begins to understand a partner's gestures of pointing (Butterworth, 1991). The implications of both achievements are, again, (a) that the child recognizes the partner as an agent with whom it is possible to communicate (why wish to show something to an entity which is not able to share this declarative intent?), but also (b) that she recognizes that the partner does not share all of her mental states with her, and that she therefore needs to actively do something if she wants to share her mental states with him.

Conversely, she also begins to realize that certain actions of a partner's (but not all of them) may be aimed at making some of his mental state shared with her. Given that she now realizes that the other human beings have mental states of their own, independent of those that she has, she may also become curious of what these other mental states will do, and therefore begin to observe the others' actions and actively try to understand them.

Another cue that the child has begun to discriminate between the mental states that different individuals entertain is provided by social referencing. This is the use that a child makes of an adult's emotional expressions as a guide for her behavior in ambiguous situations (Moses, Baldwin, Rosicky, \& Tidball, 2001): in doing this, she proves capable of recognizing the partner as an autonomous agent who entertains his own (authoritative and reliable) interpretation of the environment and may wish to communicate it.

Certain features of the child's understanding of imitation also point at the same idea: 11-monthold babies realize that they are being imitated by an adult, and repeat the acts that have been imitated, so to have the imitation acted again (Premack \& James Premack, 1994).

The child's talk also points at a capability of recognizing other persons as autonomous agents. Starting from 12 to 18 months of age, children begin to use words like want, wish, hope, etc. in everyday conversation to refer to mental states of their own and of the partner's (Repacholi \& Gopnik, 1997). They also begin to talk and act on the grounds that different persons may have different desires toward different objects (for example, that I desire the cake while you desire the ice-cream - the ability to understand that different persons may have different attitudes toward the same object is a later acquisition; Repacholi \& Gopnik, 1997). Starting from 2.5 years, they also begin to use verbs like think and know to refer to the beliefs entertained by different agents (Bartsch \& Wellman, 1995; Wellman, 1991).

The general point that we want to make is that we do not conceive of these social abilities as "precursors" to mindreading, that is, as skills or behaviors that would pave the way for some cognitive function that is not present yet, but will arrive at a later age. Instead, we conceive of them as 
manifestations of the particular form that mindreading has in early infancy; or, better yet, as manifestations of the transition from such form to that which it will take in the elder child and the adult.

\subsection{Step III}

The abilities and activities that we have described up to now do not require the forms of "metarepresentation" and reasoning that are typical of later ages (see Bermúdez, 1998; for a similar perspective on subjectivity and metarepresentation at different ages). The third and final step in the child's acquisition of mindreading thus is the ability to entertain a description (Tirassa, in press), or a commonsense theory of what her own mental states are, of what another agent's mental states are and how the two differ from each other, and to understand and apply such description in the here-and-now of the actual situation in which the child finds herself.

It is only when the child has acquired a usable awareness of the functioning of her own mind and of those of the others', and of the relations between the mind and the world, or between two minds, that this achievement becomes possible: this awareness begins to be similar to a theory in a proper sense and, in general, to what is commonly referred to as metarepresentation or metacognition.

There is, of course, a huge body of empirical evidence concerning this step in the ontogeny of mindreading: indeed, as we have discussed above, most research has focused precisely on this age (see Wellman, Cross, \& Watson, 2001). It is well-known, for example, that there is a chronological order in the types of mental states whose description the child becomes able to entertain: intentions first, then emotions, and finally beliefs.

The ability to conjure up a description of the mind finally allows the child to deal with false beliefs, belief revision, and so on. As other skills and competencies, like language and planning, also mature, she finally becomes able to pass first-order false belief tasks. Further developments will improve her ability to reason about nested mental states and therefore to solve second-order false belief tasks.

One final point that deserves discussion concerns the role that the environment may or may not have in the maturation of mindreading. To argue, as we do, that this process is a biological, innately determined one does not imply that the environment plays no role in it. On the contrary, specific types of interactions may be needed for this maturation.

Evidence pointing at a role of the environment comes from several sources. Individual differences are found in the timetable with which the various achievements in mindreading may appear (Scholl \& Leslie, 1999); these differences may be related to birth order (Dunn, Brown, Slomkowski, Tesla, \& Youngblade, 1991; Perner, Ruffman, \& Leekam, 1994) as well as to a rich exposure to elder children and adults (Lewis, Freeman, Kyriakidou, Maridaki-Kassotaki, \& Berridge, 1996). Conversely, the maturation of mindreading may be slightly delayed in children who are congenitally blind (Brown, Hobson, \& Stevenson, 1997) or deaf (Peterson \& Siegal, 1995).

This is unsurprising: the maturation of innate faculties often requires triggering or specific input from the environment or is guided, to different extents, by the external world (e.g., Bowlby, 1969; Chomsky, 1980; Fodor, 1981, 1998; Samuels, 2002; Scholl \& Leslie, 1999). Indeed, that an organ or faculty is innate means not that the environment plays no role in its maturation (or that there is no such maturation - see also Section 3), but that its development depends on how the organism's innate endowment will interact with the external environment (Lewontin, 2000). As far as cogni- 
tion is concerned, this means that an infant will only "learn" the types of knowledge, which she is designed to learn (Barkow, Cosmides, \& Tooby, 1992; Lorenz, 1965).

\section{Conclusion}

Our proposal acknowledges that human beings entertain mentalistic interactions with their caregivers from the very beginning of their life, and thus also acknowledges that early social life in the human species takes place on basically the same grounds on which adult social life does. Social interactions are as complex, rich, and healthy in infanthood as they will be in childhood and beyond.

We have argued that this is made possible by the infant's perception of her own mental states as shared with the caregivers and other partners. Such perception, which begins at birth or immediately after birth, is innate and immediately present in the infant.

There are, of course, certain specific differences with respect to the social life of an elder child or an adult. These differences depend on the infant's subjective perspective of herself as immersed in an all-social world where all of her mental states are shared with the caregivers. This provides the necessary background against which she can interact with her caregivers, communicating with them, trying to make sense of what they do and of their attempts to communicate with her, acquiring the first elements of the cultural environment in which she happens to live, and so on. Thus, the subjective sharing of mental representations provides the grounds on which both her early social interactions and her later acquisition of mindreading proper will build.

We can see basically two alternatives to our proposal. One is to posit that infant interactions differ qualitatively from those that are possible at a later age. This position proves untenable as soon as one considers its theoretical and practical implications: among the others, that communication, the acquisition of word meaning, and the acquisition of culture would become impossible. Even worse, human beings would find themselves beginning their social life as autistic individuals, only beginning to "recover" after years of life. The second alternative is to just deny ontogeny, that is, to conceive of infant cognition as identical to adult cognition, minus less effective working memory and attentional capabilities.

A biological conception of cognition makes ontogeny a viable — and, indeed, preferable — alternative to both these positions. On the one hand, contra the former, it acknowledges that children are fully part of the human species from the beginning. On the other hand, contra the latter, it acknowledges that children are children, not adults imprisoned in smaller and helpless bodies.

As mindreading undergoes its ontogeny, the child will begin to understand the mental world in terms of differences between the mental states of different agents. This will be the birth of privateness, that is, the birth of the child's perception of each agent (including herself) as bearer of mental states that can be either private or shared, and are anyway different from those entertained by other agents. This, of course, will also be the birth of private knowledge and agency.

\section{Acknowledgments}

This research was funded by the Italian Ministry of University and Research (FIRB Project, research code RBAU01JEYW). We are grateful to the anonymous reviewers of the paper, whose 
comments greatly helped us to improve it, and to William P. Banks, Editor-in-Chief of Consciousness and Cognition, for the kindness with which he treated us in the moment of need.

\section{References}

Airenti, G., Bara, B. G., \& Colombetti, M. (1993). Conversation and behaviour games in the pragmatics of dialogue. Cognitive Science, 17, 197-256.

Baillargeon, R. (1995). Physical reasoning in infants. In A. J. Premack, D. Premack, \& D. Sperber (Eds.), Causal cognition: A multidisciplinary debate. Oxford: Clarendon Press.

Barkow, J. H., Cosmides, L., \& Tooby, J. (Eds.). (1992). The adapted mind. Evolutionary psychology and the generation of culture. New York and Oxford: Oxford University Press.

Baron-Cohen, S. (1993). From attention-goal psychology to belief-desire psychology: The development of theory of mind and its dysfunction. In S. Baron-Cohen, H. Tager-Flusberg, \& D. J. Cohen (Eds.), Understanding other minds: Perspectives from autism. Oxford: Oxford University Press.

Baron-Cohen, S. (1994). How to build a baby that can read minds: Cognitive mechanisms in mindreading. Current Psychology of Cognition, 13, 513-552.

Baron-Cohen, S. (1995). Mindblindness. Cambridge, MA: MIT Press.

Barresi, J., \& Moore, C. (1996). Intentional relations and social understanding. Behavioral and Brain Sciences, 19, 107-154.

Bartsch, K., \& Wellman, H. M. (1995). Children talk about the mind. Oxford: Oxford University Press.

Bates, E., Benigni, L., Bretherton, I., Camaioni, L., \& Volterra, V. (1979). Cognition and communication from 9-13 months. In E. Bates (Ed.), The emergence of symbols. New York: Academic.

Bermúdez, J. L. (1998). The paradox of self-consciousness. Cambridge, MA: MIT Press.

Bosco, F. M., \& Tirassa, M. (1998). Sharedness as an innate basis for communication in the infant. Proceedings of the 20th Annual Conference of the Cognitive Science Society. Mahwah, NJ: Erlbaum.

Bowlby, J. (1969). Attachment and loss: I-Attachment. London: Hogarth.

Braten, S. (1992). The virtual other in infants' minds and social feelings. In H. Wold (Ed.), The dialogical alternative (pp. 77-97). Oslo: Scandinavian University Press.

Brazetlon, T. G., Koslowsky, B., \& Main, M. (1974). The origins of reciprocity: The early mother-infant interaction. In M. Lewis \& L. Rosenblum (Eds.), The effect of the infant on its caregivers. New York: Wiley.

Brown, R., Hobson, A. L., \& Stevenson, J. (1997). Are there 'autistic-like' features in congenitally blind children. Journal of Child Psychology and Psychiatry, 38, 693-704.

Butterworth, G. (1991). The ontogeny and phylogeny of joint visual attention. In A. Whiten (Ed.), Natural theories of the mind. Oxford: Blackwell.

Carassa, A., Morganti, F., \& Tirassa, M. (2004). Movement, action, and situation. In M. Alcañiz Raya \& B. Rey Solaz (Eds.), Proceedings of the 7th annual international workshop on presence. Valencia, Spain: Editorial Universidad Politécnica de Valencia.

Carassa, A., Morganti, F., \& Tirassa, M. (2005). A situated cognition perspective on presence. In B. G. Bara, L. Barsalou, \& M. Bucciarelli (Eds.), Proceedings of the 27th Annual Conference of the Cognitive Science Society. Stresa, Italy.

Carey, S. (1995). On the origin of causal understanding. In A. James Premack, D. Premack, \& D. Sperber (Eds.), Causal cognition. Oxford: Clarendon.

Charlesworth, W. R., \& Kreutzer, M. A. (1973). An ethological approach to research on facial expression. In P. Ekman (Ed.), Darwin and facial expression. New York: Academic Press.

Chomsky, N. (1980). Rules and representations. New York: Columbia University Press.

Clark, H. H., \& Marshall, C. R. (1981). Definite reference and mutual knowledge. In A. K. Joshi, B. L. Webber, \& I. A. Sag (Eds.), Elements of discourse understanding. Cambridge: Cambridge University Press.

Colombetti, M. (1993). Formal semantics for mutual belief. Artificial Intelligence, 62, 341-353.

Dunn, J., Brown, J., Slomkowski, C., Tesla, C., \& Youngblade, L. (1991). Young children's understanding of other people's feelings and beliefs: Individual differences and their antecedents. Child Development, 62, 1352-1366. 
Edelman, G. M. (1992). Bright air, brilliant fire: On the matter of the mind. New York: Basic Books.

Flavell, J. H., Everett, B. A., Croft, K., \& Flavell, E. R. (1981). Young children's knowledge about visual perception. Developmental Psychology, 17, 99-103.

Fodor, J. A. (1975). The language of thought. New York: Crowell.

Fodor, J. A. (1981). The present status of the innateness controversy. In Representations. Cambridge, MA: MIT Press. Fodor, J. A. (1987). Psychosemantics. The problem of meaning in the philosophy of mind. Cambridge, MA: MIT Press.

Fodor, J. A. (1992). A theory of the child's theory of mind. Cognition, 44, 283-296.

Fodor, J. A. (1998). Concepts. Where cognitive science went wrong. Oxford: Oxford University Press.

Freud, S. (1911). Formulation on the two principles of mental functioning. In J. Strachey (Ed.), Sigmund Freud, ( Vol. 12, pp. 213-216). London: Hogarth Press.

Gallese, V., \& Goldman, A. (1998). Mirror neurons and the simulation theory of mindreading. Trends in Cognitive Science, 2, 493-501.

Garfield, J. L., Peterson, C. C., \& Perry, T. (2001). Social cognition, language acquisition and the development of the theory of mind. Mind and Language, 16, 494-541.

Gergely, G., \& Watson, J. (1996). The social biofeedback model of parental affect-mirroring. International Journal of Psycho-Analysis, 77, 1181-1212.

Gergely, G., \& Watson, J. (1999). Early social-emotional development: Contingency perception and the social biofeedback model. In P. Rochat (Ed.), Early social cognition: Understanding others in the first months of life (pp. 101-137). Hillsdale, NJ: Lawrence Erlbaum.

Goldman, A. (1993). The psychology of folk psychology. Behavioral and Brain Sciences, 16, 15-28.

Gopnik, A. (1993). How we know our minds. Behavioral and Brain Sciences, 16, 1-14.

Gordon, R. M. (1996). Radical simulationism. In P. Carruthers \& P. K. Smith (Eds.), Theories of theories of mind. Cambridge: Cambridge University Press.

Grice, H. P. (1989). Studies in the way of words. Cambridge, MA: Harvard University Press.

Hains, S. M. J., \& Muir, D. W. (1996). Infant sensitivity to adult eye direction. Child Development, 67, 1940-1949.

Harris, P. L. (1991). The work of the imagination. In A. Whiten (Ed.), Natural theories of the mind. Oxford: Blackwell.

Haviland, J. M., \& Lelwica, M. (1987). The induced effect response. Developmental Psychology, 23, $97-104$.

Hobson, R. P. (1993). Autism and the development of mind. Hove, UK: Erlbaum.

Lempers, J. D., Flavell, E. R., \& Flavell, J. H. (1977). The development in very young children of tacit knowledge concerning visual perception. Genetic Psychology Monographs, 95, 3-53.

Leslie, A. M. (1987). Pretense and representation: The origins of theory of mind. Psychological Review, 94, 412-426.

Leslie, A. M. (1994a). ToMM, ToBy, and agency. In L. Hirschfield \& S. Gelman (Eds.), Mapping the mind. New York: Cambridge University Press.

Leslie, A. M. (1994b). Pretending and believing: Issues in the theory of ToMM. Cognition, 50, $211-238$.

Lewis, C., Freeman, N., Kyriakidou, C., Maridaki-Kassotaki, K., \& Berridge, D. (1996). Social influences on false belief access: Specific sibling influences or general apprenticeship? Child Development, 67, 2930-2947.

Lewontin, R. (2000). The triple helix: Gene, organism and environment. Cambridge, MA: Harvard University Press.

Lorenz, K. (1965). Evolution and modification of behavior. Chicago and London: The University of Chicago Press.

Meltzoff, A. N., \& Gopnik, A. (1993). The role of imitation in understanding persons and developing theories of mind. In S. Baron-Cohen, H. Tager-Flusberg, \& D. Cohen (Eds.), Understanding other minds. Oxford: Oxford University Press.

Meltzoff, A. N., \& Moore, M. K. (1983). Newborn infants imitate adult facial gestures. Child Development, 54, $702-709$.

Meltzoff, A. N., \& Moore, M. K. (1989). Imitation in newborn infants: Exploring the range of gestures imitated and the underlying mechanisms. Developmental Psychology, 25, 954-962.

Meltzoff, A. N., \& Moore, M. K. (1997). Explaining facial imitation: Theoretical model. Early Development and Parenting, 6, 179-192.

Moses, L. J., Baldwin, D. A., Rosicky, J. G., \& Tidball, G. (2001). Evidence for referential understanding in the emotions domain at twelve and eighteen months. Child Development, 72, 718-735.

Morton, J., \& Johnson, M. H. (1991). CONSPECT and CONLEARN: A two process theory of infant face recognition. Psychological Review, 98, 164-181. 
Murray, L., \& Trevarthen, C. (1985). Emotional regulation of interaction between 2-month-olds and their mother. In T. M. Field \& N. A. Fox (Eds.), Social perception in infant. Norwood, NJ: Meredith.

Papousek, H., \& Papousek, M. (1974). Mirror-image and self recognition in young infants: A new method of experimental analysis. Developmental Psychobiology, 7, 149-157.

Papousek, H., \& Papousek, M. (1979). Early ontology of human social interaction: Its biological roots and social dimension. In M. von Cranach et al. (Eds.), Human ethology: Claim and limits of a new discipline. Cambridge: Cambridge University Press.

Perner, J., Ruffman, T., \& Leekam, S. (1994). Theory of mind is contagious: You can take it from your sibs. Child Development, 65, 1228-1238.

Peterson, C., \& Siegal, M. (1995). Deafness, conversation and theory of mind. Journal of Child Psychology and Psychiatry, 36, 459-474.

Piaget, J. (1936). La naissance de l'intelligence chez l'enfant. Neuchatel: Delachaux \& Niestlé. [Translation: The origins of intelligence in children. New York: International Universities Press, 1952].

Premack, D. (1990). The infant's theory of self-propelled objects. Cognition, 36, 1-16.

Premack, D., \& James Premack, A. (1994). Why animals have neither culture nor history. In T. Ingold (Ed.), Companion encyclopedia of anthropology. London: Routledge.

Premack, D., \& Woodruff, G. (1978). Does the chimpanzee have a theory of mind. Behavioral and Brain Sciences, 1, 512-526.

Repacholi, B. M., \& Gopnik, A. (1997). Early reasoning about desires: Evidence from 14- and 18-month olds. Developmental Psychology, 33, 12-21.

Rizzolatti, G., Fadiga, L., Gallese, V., \& Fogassi, L. (1996). Premotor cortex and the recognition of motor actions. Cognitive Brain Research, 3, 131-141.

Rochat, P., \& Morgan, R. (1995). Spatial determinants in the perception of self-produced leg movements in 3- to 5month-old infants. Developmental Psychology, 31, 626-636.

Samuels, R. (2002). Nativism in cognitive science. Mind and Language, 17, 233-265.

Scaife, M., \& Bruner, J. (1975). The capacity for joint visual attention in the infant. Nature, 235, 265-266.

Scholl, B. J., \& Leslie, A. M. (1999). Modularity, development and theory of mind. Mind and Language, 14, 131-153.

Searle, J. R. (1983). Intentionality: An essay in the philosophy of mind. Cambridge: Cambridge University Press.

Searle, J. R. (1992). The rediscovery of the mind. Cambridge, MA: MIT Press.

Searle, J. R. (1995). The construction of social reality. New York: Free Press.

Spelke, E. (1994). Initial knowledge: Six suggestions. Cognition, 50, 431-445.

Spelke, E., \& Van de Walle, G. (1993). Perceiving and reasoning about objects: Insigths from infants. In N. Eilan, W. Brewer, \& R. McCarthy (Eds.), Spatial representation. New York: Basil Blackwell.

Stern, D. N. (1985). The interpersonal world of the infant. New York: Basic Books.

Stern, D. N. (1995). Self/other differentiation in the domain of intimate socio-affective interaction: Some considerations. In P. Rochat (Ed.), The Self in infancy: Theory and research (pp. 419-429). Amsterdam: Elsevier.

Stern, D. N., Jaffe, J., Beebe, B., \& Bennett, S. K. (1975). Vocalizing in unison and alternation: Two modes of communication within the mother-infant dyad. In D. Aaronson \& R. W. Rieber (Eds.), Developmental psycholinguistics and communication disorders. New York: New York Academy of Sciences.

Thompson, R. (1998). Empathy and its origins in early development. In S. Braten (Ed.), Intersubjective communication and emotion in early ontogeny (pp. 144-157). Paris: Cambridge University Press.

Tirassa, M. (1997). Mental states in communication. Proceedings of the 2nd European Conference on Cognitive Science. Manchester, UK.

Tirassa, M. (1999a). Communicative competence and the architecture of the mind/brain. Brain and Language, 68, 419-441.

Tirassa, M. (1999b). Taking the trivial doctrine seriously: Functionalism, eliminativism, and materialism. Behavioral and Brain Sciences, 22, 851-852.

Tirassa, M. (in press). Agencies. In: L. A. Pérez Miranda \& J. M. Larrazabal (Eds.), Advantages in Cognitive Science. Dordrecht: Kluwer.

Tirassa, M., Carassa, A., \& Geminiani, G. (2000). A theoretical framework for the study of spatial cognition. In S. Ó Nualláin (Ed.), Spatial cognition Foundations and applications. Amsterdam/Philadelphia: Benjamins. 
Tomasello, M. (1995). Joint attention as social cognition. In C. Moore \& P. Dunham (Eds.), Joint attention: Its origins and role in development. Hillsdale, NJ: Erlbaum.

Tomasello, M. (1999). The cultural origins of human cognition. Cambridge: Harvard University Press.

Tomasello, M., Carpenter, M., Call, J., Behne, T., \& Moll, H. (in press). Understanding and sharing intentions: The ontogeny and phylogeny of cultural cognition. Behavioral and Brain Sciences.

Tomasello, M., \& Rakoczy, H. (2003). What makes human cognition unique. From individual to shared to collective intentionality. Mind and Language, 8, 121-147.

Trevarthen, C. (1977). Descriptive analyses of infant communicative behavior. In H. Schaeffer (Ed.), Determinants of infant behavior. London: Academic.

Trevarthen, C. (1979). Communication and cooperation in early infancy. In M. Bullowa (Ed.), Before speech. Cambridge: Cambridge University Press.

Trevarthen, C. (1993). The function of emotions in early infant communication and development. In J. Nadel \& L. Camaioni (Eds.), New perspectives in early communicative development (pp. 48-81). New York: Routledge.

Trevarthen, C. (1998). The concept and foundations of infant intersubjectivity. In S. Braten (Ed.), Intersubjectivity communication and emotion in early ontogeny (pp. 15-46). Cambridge: Cambridge University Press.

Trevarthen, C. (2001). The neurobiology of early communication: Intersubjective regulations in human brain development. In A. F. Kalverboer \& A. Gramsbergen (Eds.), Handbook on brain and behavior in human development. Dordrecht, The Neverlands: Klewer Academic Publisher.

Trevarthen, C., \& Aitken, K. J. (2001). Infant intersubjectivity: Research, theory and clinical applications. Journal of Psychological Psychiatry, 42, 3-48.

Tronick, E., Als, H., \& Adamson, L. (1979). Structure of early face-to-face communicative interactions. In M. Bullowa (Ed.), Before speech. New York: Cambridge University Press.

Varela, F. J., Thompson, E., \& Rosch, E. (1991). The embodied mind. Cognitive science and human experience. Cambridge, MA: MIT Press.

Wellman, H. M. (1990). The child's theory of mind. Cambridge: MIT Press.

Wellman, H. M. (1991). From desires to beliefs: Acquisition of a theory of mind. In A. Whiten (Ed.), Natural theories of the mind. Oxford: Blackwell.

Wellman, H. M., Cross, D., \& Watson, J. (2001). Meta-analysis of theory-of-mind development: The truth about false belief. Child Development, 72, 655-684.

Whiten, A. (1994). Grades of mindreading. In C. Lewis \& P. Mitchell (Eds.), Children's early understanding of the mind: Origins and development. Hillsdale: Erlbaum.

Wimmer, H., \& Perner, J. (1983). Beliefs about beliefs. Representation and constraining functions of wrong beliefs in young children's understanding of deception. Cognition, 13, 103-128.

Woodward, A. (1998). Infants selectively encode the goal object of an actor's reach. Cognition, 69, 1-34. 